\title{
Standardization of the measurement of transfer factor: Allowance for water vapour in the analysis of helium concentration
}

\section{To the Editor:}

The official statements of the European Respiratory Society (ERS) [1] and American Thoracic Society (ATS) [2] consistently recommended some corrections before adopting the measured values of alveolar helium fraction $(F \mathrm{~A}, \mathrm{He})$ in the "alveolar sample" for the calculation of alveolar volume $(V \mathrm{~A})$. I refer to the measurement of the carbon monoxide transfer factor by the single-breath method. As the expired gas is passed first through $\mathrm{CO}_{2}$ and $\mathrm{H}_{2} \mathrm{O}$ absorbers and then to the helium analyser, this reduces the total volume of the sample and the percentage of helium is overestimated. The recommendations include a correction for the dead space of the sampling bag, and for the $\mathrm{CO}_{2}$ absorption (measured or assumed), but none for $\mathrm{H}_{2} \mathrm{O}$ absorption.

Conversely, the latter is included in the Guidelines for the Measurement of Respiratory Function, produced by the British Thoracic Society (BTS) and Association of Respiratory Technicians and Physiologists (ARTP) [3], which state "the percentage of $\mathrm{H}_{2} \mathrm{O}$ in the sample may be estimated from tables and is dependent on the ambient temperature". Assuming a full water vapour saturation of the alveolar sample, a rough calculation suggests that a $6 \%$ correction at $37^{\circ} \mathrm{C}$ would decline to about $2 \%$ at $20-22^{\circ} \mathrm{C}$. Ridiculous? May be. Nevertheless, these guidelines are offered as "a simpler instruction manual ... for immediate referral".

I should be happier with a statement from the ERS Working Party and I thank you in advance if you will kindly convey my question. Of course the question is of interest to only a minority, i.e. those who measure the "effective alveolar volume" and use a thermal conductivity helium analyser.

\section{References}

1. Cotes JE, Chinn DJ, Quanjer PhH, Roca J, Yernault JC. Standardization of the measurement of transfer factor (diffusing capacity). Report of working party "Standardization of lung function tests", 1993 update. Official statement European Respiratory Society. Eur Respir J 1993; 6 (Suppl. 16): 41-53.

2. DL,CO Standardization Conference. Single-breath carbon monoxide diffusing capacity: recommendations for a standard technique. Am Rev Respir Dis 1987; 136: 1299-1307.

3. The British Thoracic Society and the Association of Respiratory Technicians and Physiologists: Guidelines for the Measurement of Respiratory Function. Respir Med 1994; 88: 165-194.

\section{A. Rizzo}

Ospedale Carvello, I-90146 Palermo, Italy.

\section{REPLY}

\section{From the authors:}

We thank Dr Rizzo for his letter, in which he points out that for the analysis of alveolar helium concentration, the European guidelines neglect the error associated with aqueous vapour pressure. The concentration is used in the estimation of alveolar volume, and any error could contribute to differences between published reference values for $T \mathrm{~L}, \mathrm{CO}$.

Assuming a laboratory temperature of $20^{\circ} \mathrm{C}$, the error caused by neglecting water vapour is approximately $2 \%$; hence, there is a case for increasing the value for $\mathrm{K}$ by this amount in equation (9) of the standardization document [1]. In practice, the position is less simple. The equation already contains terms for instrument dead space, which can be measured, and for anatomic dead space and "alveolar" partial pressure of carbon dioxide, which are usually estimated. In the circumstances of the test, the last of these can have wide confidence limits,

such that the error from an inappropriate assumption could cancel out that due to neglect of water vapour.

We agree with Dr Rizzo that an allowance for water vapour would be appropriate, but recommend that the correction only be applied in circumstances when the partial pressure of carbon dioxide in the "alveolar" sample can also be measured. Either way, it is important that the conventions which are used should be specified.

\section{Reference}

1. Cotes JE, Chinn DJ, Quanjer PhH, Roca J, Yernault J-C. Standardization of the measurement of transfer factor (diffusing capacity). Report of working party "Standardization of lung function tests", 1993 update. Official statement European Respiratory Society. Eur Respir J 1993; 6 (Suppl. 16): 41-53.

J.E. Cotes, D.J. Chin, Ph.H. Quanjer, J. Roca, J-C. Yernault

Working party on Standardization of Lung Function Tests for the ERS. 